\title{
Evaluation of Self Management Behavior of Chronic Kidney Disease Patients
}

\author{
Sook Hui Phua ${ }^{1}$, Nur Akmar Taha ${ }^{1}$, Kiew Bing Pau ${ }^{2}$, Wei Yen Kong ${ }^{3}$ \\ 1.Faculty of Pharmacy, Universiti Kebangsaan Malaysia, 43600 UKM, Bangi Selangor, Malaysia \\ 2.Pharmacy Department, Universiti Kebangsaan Malaysia Medical Centre, Jalan Yaacob Latif, Bandar Tun Razak, 56000 Cheras, \\ Kuala Lumpur, Malaysia \\ 3.Nephrology Unit, Medical Department, Universiti Kebangsaan Malaysia Medical Centre, Jalan Yaacob Latif, Bandar Tun Razak, \\ 56000 Cheras, Kuala Lumpur, Malaysia
}

\begin{abstract}
CKD (chronic kidney disease) is a progressive disease. If it is left untreated, it can eventually result in end stage renal failure and necessitate dialysis or kidney transplantation. There is no cure for CKD; instead a great deal of self management over time is essential. The purpose is to evaluate self management behaviour of patients at different stages of CKD. A total of $300 \mathrm{CKD}$ patients were recruited in this cross sectional study from March to July 2015 at nephrology clinic of a tertiary care setting using convenience sampling. Self management behaviour score was determined using in Partners in Health scale and was then compared at different stages of CKD. Demographic and clinical factors contributing to self management behaviour were determined. Results: There was a significant difference in age $(p<0.001)$, gender $(p<0.001)$, education level $(p<0.001)$, marital status $(p<0.001)$, duration of illness $(p<0.001)$ and number of co-morbidities $(p<0.001)$ among CKD stages. A significant difference in self management behaviour mean score was found among CKD stages $(p<0.001)$. Post hoc analysis showed self management behaviour mean score for Stage I (mean \pm SD: $77.81 \pm 9.41$ ) was significantly higher than Stage IV (mean \pm SD: $70.53 \pm 13.91$ ) and Stage V (mean \pm SD: $69.54 \pm 12.31$ ). Self management behaviour mean score for Stage II (mean \pm SD: $78.46 \pm 10.01$ ) was significantly higher than Stage IV and Stage V. Multiple linear regression revealed education level $(p<0.001)$ and number of co-morbidities $(p=0.01)$ as significant predictors of self management behaviour. It can be concluded that special attention should be focused on patients at late stage of CKD, especially those with diabetic nephropathy; low education level and multiple co-morbidities to improve self management behaviour.
\end{abstract}

Key words: Self management behaviour, chronic kidney disease, predictors, demographic factors, clinical factors.

\section{Introduction}

The growing number in incidence and prevalence of CKD (chronic kidney disease) and ESRF (end stage renal failure) has now become a global challenge. The global prevalence of CKD is estimated to be $11 \sim 13 \%$ [1]. It has been estimated that approximately 3,200,000 of patients have been treated for ESRF globally at the end of 2013 and the number continues to increase at a rate faster than world population growth rate at $6 \%$ [2]. Progression of late stage CKD is associated with increased morbidity and mortality

Corresponding author: Wei Yen Kong, (Consultant Nephrologist/Head of Nephrology and Dialysis Unit), research field: general nephrology. which in turn result in decreased quality of life and premature death. Management of patients with CKD and ESRF is costly and it has placed an enormous burden to healthcare system. In developed countries, the expenditure of ESRF treatment accounted for about 2 3\% of total healthcare expenditure but ESRF patients represent only $0.1 \sim 0.2 \%$ of the total population. Treatment expenditure accounted for $6.3 \%$ of the Medicare budget in USA in 2010 [3].

Long nature of the disease along with its progression and co-existence of multiple co-morbidities and complications such as anaemia, malnutrition, infection, mineral and bone disorder, reduced cognitive function, depression, cardiovascular 
disease, dyslipidemia and diabetes mellitus have made the management of CKD much complicated [4]. The complexity of the disease and treatment has caused behavioural self-management inevitably challenging as patients have to manage numerous medications, diet and lifestyle modification and to attend multiple medical appointments. Current CKD research has mostly emphasized on pharmacological treatment and disease mechanism discoveries. There are limited studies that focus on self-management strategies which address the psychological and behavioural complexities inherent in any chronic diseases and it is vital for effective management of CKD, which is a long lasting, frustrating and progressive disease. It has been suggested that progression of disease may be partly delayed with good self management $[5,6]$ and the prevention of renal progression is essential to improve the clinical outcome of CKD patients [7]. Therefore, in order to minimize the negative impact of CKD on the individual and to slow the disease progression, it is important for the patients to engage in effective self-management. Self-management is the ability of the patient to deal with all that a chronic disease entails. It involves individuals working in partnership with their healthcare providers to know their condition and various treatment options, negotiate a care plan, engage in activities that protect and promote health, monitor and manage the symptoms and signs of illnesses and manage the impact of illness on physical functioning, emotions and internal relationships and adhering to treatment regimens $[8,9]$.

There is no cure for chronic kidney disease; instead management over time is essential. For effective treatment, patients are encouraged to involve actively in the management of their disease and good self management has been associated with positive outcomes. However, there is a lack of study on evaluation of self management behavior status of patients with chronic kidney disease in Malaysia. This background information can be useful for the development of targeted self management interventions in future towards achieving optimal outcomes.

This study aims to evaluate self-management behaviour of patients at different stages of chronic kidney disease.

\section{Materials and Methods}

\subsection{Study Setting}

This cross sectional study was approved by local research ethics committee (UKM 1.5.3.5/244/NF-006-15). It was conducted at nephrology clinic of a tertiary care setting. The study subjects were recruited from March 2015 to July 2015.

\subsection{Study Subjects}

The inclusion criteria in this study were those with CKD Stage I to V including dialysis, diagnosed with CKD for at least 12 months and aged $\geq 18$ years old. The exclusion criteria were those with mental illness or mental incapability and not consented. The study subjects were selected using convenience sampling method. The sample size required was 300 and was calculated based on population size estimation of target population of 1,400 patients [10].

\subsection{Data Collection and Outcome Measure}

Demographic characteristics such as age, gender, race, education level, marital status and employment status were collected. Clinical characteristics such as staging of CKD, duration of illness and number of co-morbidities were obtained. Study outcome was measured as self-management behaviour score.

\subsection{Study Instrument}

PIH (partners in health) scale was used to determine general self-management behaviour of patients at different stages of chronic kidney disease [8]. It is a validated 12-item questionnaire addressing different aspects of self-care for chronic disease including disease related knowledge, sharing in decision, 
interacting with health care providers, taking medications, understanding of and ability to monitor symptoms and respond to symptoms changes, attending clinic appointments, managing effect on physical activities, managing emotion, managing relations with others and managing to live a healthy life. Each item was rated by study subjects using Likert scale from 0 indicating poor self management to eight indicating good self-management. Total scores for each patient were summed up ranging from 0 to 96 with higher scores representing better self-management. The PIH scale was translated into Malay with Cronbach's alpha of 0.801 , denoting a reasonable internal consistency.

\subsection{Staging of CKD Classification}

Staging of CKD was based on National Kidney Foundation Kidney Disease Outcomes Quality Initiative classification as shown in Table 1 [11]. In this study, Stage $\mathrm{V}$ was further divided into non dialysis (V) and dialysis (VD). The eGFR was determined by two calculations with three months apart using CKD-EPI (chronic kidney disease epidemiology collaboration) equation [12].

\subsection{Study Procedure}

List of outpatient attendees before clinic started was obtained. Then, patients were screened based on inclusion and exclusion criteria. Overview of study was provided to the patients. After that, consents from participants were obtained and confidentiality was assured. Demographic and clinical characteristics were obtained from medical records and by interviewing patients. Self-management behaviour was then assessed by using Partner in Health scale

\subsection{Statistical Analysis}

Demographic and clinical characteristics were compared among the CKD stages. For categorical variables, descriptive statistics were expressed in absolute values and percentage, $n(\%)$. Differences in gender, education level, marital status and employment status variables were evaluated using chi square test whilst chi square test with Yate's correction was used to analyze differences in race since there were at least $20 \%$ of expected frequencies less than five. For continuous variables, normality of data distribution was tested with acceptable range of skewness $-0.8 \sim 0.8$ and kurtosis $-3.0 \sim 3.0$. Since skewness and kurtosis were within the acceptable range, comparison analysis of continuous variables was conducted using one way ANOVA test and data were presented as mean \pm SD (standard deviation). Self-management behaviour score was compared among the CKD stages. Normality of data distribution was tested with acceptable range of skewness $-0.8 \sim 0.8$ and kurtosis $-3.0 \sim 3.0$. Since skewness and kurtosis were within the acceptable range, one way ANOVA with post hoc analysis using Tukey HSD was conducted for comparison analysis and data were presented as mean \pm SD. Simple linear regression was carried out to identify significant predictors of self management behaviour followed by multiple linear regression using forward method. All data obtained were analysed by using the Statistical Package for the Social Sciences (SPSS Inc., Chicago, IL) Version 22.0. All statistical tests were two-tailed. A $p$-value of $<$ 0.05 was considered statistically significant.

\section{Results}

A total of 300 subjects with CKD were recruited in this study. Comparison of demographic and clinical characteristics of the study subjects at different CKD

Table 1 Staging of chronic kidney disease.

\begin{tabular}{ll}
\hline Stage & eGFR $\left(\mathrm{mL} / \mathrm{min} / 1.73 \mathrm{~m}^{2}\right)$ \\
\hline I & $\geq 90$ with kidney damage $\mathrm{a}^{\mathrm{a}}$ \\
II & $60 \sim 89$ \\
III & $30 \sim 59$ \\
IV & $15 \sim 29$ \\
V & $<15$ or renal replacement therapy \\
\hline a & Kidney damage was manifested by either pathological
\end{tabular}

Kidney damage was manifested by either pathological abnormalities or markers of kidney damage including abnormalities in the composition of the blood or urine, or abnormalities in imaging tests. 
Table 2 Demographic and clinical characteristics of study subjects at different stages of chronic kidney disease $(n=300)$.

\begin{tabular}{|c|c|c|c|c|c|c|c|c|}
\hline \multirow{2}{*}{ Subjects $(n)$} & Stage I & Stage II & Stage III & Stage IV & Stage $V^{b}$ & Stage $\mathrm{VD}^{\mathrm{c}}$ & Statistic & $p$-value \\
\hline & 57 & 39 & 62 & 53 & 39 & 50 & \multirow[b]{2}{*}{$F=48.849$} & \multirow[b]{2}{*}{$<0.001 * \mathrm{~d}$} \\
\hline Age in years $($ Mean \pm SD) & $34.23 \pm 9.96$ & $\begin{array}{l}43.97 \pm \\
11.98 \\
\end{array}$ & $\begin{array}{l}57.82 \pm \\
14.11 \\
\end{array}$ & $\begin{array}{l}66.66 \pm \\
12.14 \\
\end{array}$ & $\begin{array}{l}65.10 \pm \\
12.05\end{array}$ & $\begin{array}{l}51.88 \pm \\
15.83 \\
\end{array}$ & & \\
\hline \multicolumn{9}{|l|}{ Gender $n(\%)$} \\
\hline $\begin{array}{l}\text { Male } \\
\text { Female }\end{array}$ & $\begin{array}{l}10(17.5) \\
47(82.5) \\
\end{array}$ & $\begin{array}{l}7(17.9) \\
32(82.1) \\
\end{array}$ & $\begin{array}{l}37(59.7) \\
25(40.3) \\
\end{array}$ & $\begin{array}{l}28(52.8) \\
25(47.2) \\
\end{array}$ & $\begin{array}{l}22(56.4) \\
17(43.6) \\
\end{array}$ & $\begin{array}{l}19(38) \\
31(62) \\
\end{array}$ & $\begin{array}{l}\chi^{2}= \\
37.553\end{array}$ & $<0.001 *$ \\
\hline \multicolumn{9}{|l|}{ Race $n(\%)$} \\
\hline $\begin{array}{l}\text { Malay } \\
\text { Chinese } \\
\text { Indian }\end{array}$ & $\begin{array}{l}26(45.6) \\
29(50.9) \\
2(3.5) \\
\end{array}$ & $\begin{array}{l}19(48.7) \\
19(48.7) \\
1(2.6) \\
\end{array}$ & $\begin{array}{l}30(48.4) \\
27(43.5) \\
5(8.1) \\
\end{array}$ & $\begin{array}{l}24(45.3) \\
28(52.8) \\
1(1.9) \\
\end{array}$ & $\begin{array}{l}17(43.6) \\
19(48.7) \\
3(7.7) \\
\end{array}$ & $\begin{array}{l}30(60) \\
19(38) \\
1(2)\end{array}$ & $\begin{array}{l}\text { Yate's } \chi^{2}= \\
4.45\end{array}$ & 0.925 \\
\hline \multicolumn{9}{|l|}{ Education level $n(\%)$} \\
\hline $\begin{array}{l}\text { No formal education or } \\
\text { primary school education } \\
\text { High school education } \\
\text { Higher education }\end{array}$ & $\begin{array}{l}21(36.8) \\
33(57.9) \\
\end{array}$ & $\begin{array}{l}15(38.5) \\
17(43.6) \\
\end{array}$ & $\begin{array}{l}27(43.5) \\
21(33.9) \\
\end{array}$ & $\begin{array}{l}25(47.2) \\
8(15.1) \\
\end{array}$ & $\begin{array}{l}13(33.3) \\
10(25.6) \\
\end{array}$ & $\begin{array}{l}21(42.0) \\
19(38.0) \\
\end{array}$ & $\begin{array}{l}\chi^{2}= \\
36.070\end{array}$ & $<0.001^{*}$ \\
\hline \multicolumn{9}{|l|}{ Marital status $n(\%)$} \\
\hline $\begin{array}{l}\text { Not married } \\
\text { Married } \\
\text { Divorced/widowed }\end{array}$ & $\begin{array}{l}27(47.4) \\
28(49.1) \\
2(3.5) \\
\end{array}$ & $\begin{array}{l}10(25.6) \\
27(69.2) \\
2(5.1) \\
\end{array}$ & $\begin{array}{l}2(3.2) \\
53(85.5) \\
7(11.3) \\
\end{array}$ & $\begin{array}{l}4(7.5) \\
35(66.0) \\
14(26.4) \\
\end{array}$ & $\begin{array}{l}0(0) \\
32(82.1) \\
7(17.9) \\
\end{array}$ & $\begin{array}{l}10(20.0) \\
33(66.0) \\
7(14.0) \\
\end{array}$ & $\begin{array}{l}\chi^{2}= \\
68.124\end{array}$ & $<0.001^{*}$ \\
\hline \multicolumn{9}{|l|}{ Employment status $n(\%)$} \\
\hline $\begin{array}{l}\text { Retired } \\
\text { Employed } \\
\text { Unemployed }\end{array}$ & $\begin{array}{l}0(0) \\
38(66.7) \\
19(33.3)\end{array}$ & $\begin{array}{l}1(2.6) \\
23(59.0) \\
15(38.5)\end{array}$ & $\begin{array}{l}27(43.5) \\
23(37.1) \\
12(19.4)\end{array}$ & $\begin{array}{l}26(49.1) \\
11(20.8) \\
16(30.2)\end{array}$ & $\begin{array}{l}23(59.0) \\
4(10.3) \\
12(30.8)\end{array}$ & $\begin{array}{l}12(24.0) \\
14(28.0) \\
24(48.0)\end{array}$ & \multicolumn{2}{|c|}{$\chi^{2}=87.133<0.001^{*}$} \\
\hline $\begin{array}{l}\text { Duration of illness in } \\
\text { years (Mean } \pm \text { SD) }\end{array}$ & $9.12 \pm 5.83$ & $11.10 \pm 6.29$ & $13.48 \pm 7.90$ & $15.75 \pm 7.66$ & $17.92 \pm 9.14$ & $11.48 \pm 7.76$ & $F=8.879$ & $<0.001^{* \mathrm{e}}$ \\
\hline $\begin{array}{l}\text { No. of co-morbidities } \\
(\text { Mean } \pm \text { SD) }\end{array}$ & $1.53 \pm 0.91$ & $1.92 \pm 1.18$ & $3.63 \pm 1.39$ & $3.55 \pm 1.14$ & $3.62 \pm 1.16$ & $2.54 \pm 1.28$ & $F=31.635$ & $<0.001 *^{\mathrm{f}}$ \\
\hline
\end{tabular}

$F=$ one way ANOVA;

$\chi^{2}=$ chi square test;

Yate's $\chi^{2}=$ chi square test with Yate's correction;

$\mathrm{SD}=$ standard deviation;

${ }^{\mathrm{b}}$ non dialysis;

c dialysis;

$* p<0.05$ denoted statistical significant difference;

${ }^{\mathrm{d}}$ Post hoc analysis: I vs. II ( $\left.p=0.004\right)$; I vs. III ( $\left.p<0.001\right)$; I vs. IV $(p<0.001)$; I vs. V $(p<0.001)$; I vs. VD $(p<0.001)$; II vs. III ( $p$ $<0.001)$; II vs. IV $(p<0.001)$; II vs. V $(p<0.001)$; II vs. VD $(p=0.049)$; III vs. IV $(p=0.004)$; IV vs. VD $(p<0.001)$; V vs. VD $(p$ $=0.001$ );

${ }^{\mathrm{e}}$ Post hoc analysis: I vs. III $(p=0.020)$; I vs. IV $(p<0.001)$; I vs. V $(p<0.001)$; II vs. IV $(p=0.039)$; II vs. V ( $\left.p=0.001\right)$; III vs. V $(p=0.045) ; \mathrm{IV}$ vs. VD $(p=0.045) ; \mathrm{V}$ vs. VD $(p=0.001)$

${ }^{\mathrm{f}}$ Post hoc analysis: I vs. III ( $\left.p<0.001\right)$; I vs. IV ( $\left.p<0.001\right)$; I vs. V $(p<0.001)$; I vs. VD $(p<0.001)$; II vs. III $(p<0.001)$; II vs. IV $(p<0.001)$; II vs. V $(p<0.001)$; III vs. VD $(p<0.001)$; IV vs. VD $(p<0.001)$; V vs. VD $(p<0.001)$.

stages was presented in Table 2. There was a significant difference in age among CKD stages $(p<$ 0.001). Post hoc analysis indicated that age for Stage I (mean \pm SD: $34.23 \pm 9.96$ ) was significantly younger than Stage II (mean \pm SD: $43.97 \pm 11.98)$, Stage III $($ mean \pm SD: $57.82 \pm 14.11)$, Stage IV (mean \pm SD: $66.66 \pm 12.14)$, Stage V (mean \pm SD: $65.10 \pm 12.05)$ and Stage VD (mean \pm SD: $51.88 \pm 15.83)$. Age for
Stage II was significantly younger than Stage III, Stage IV, Stage V and Stage VD. Age for Stage III was significantly younger than Stage IV. Stage VD was significantly younger than Stage IV and Stage V. There was also a significant difference in gender distribution among CKD stages $(p<0.001)$. Male subjects were fewer at Stage I $(n=17.5 \%)$, Stage II ( $n$ $=17.9 \%)$ and Stage VD $(n=38 \%)$. No significant 
difference was noted in race distribution ( $p=0.925)$. A significant difference in education level was found among CKD stages $(p<0.001)$. Stage I $(n=57.9 \%)$ and Stage II ( $n=43.6 \%$ ) had more study subjects with higher education. Whilst Stage V $(n=41 \%)$ had more study subjects with either no formal education or primary school education as compared to other CKD stages. For marital status, there was a significant difference among CKD stages $(p<0.001)$. Stage I ( $n$ $=47.4 \%)$ and Stage II $(n=25.6 \%)$ had higher proportion of not married study subjects. Stage IV ( $n$ $=26.4 \%)$ and Stage V $(n=17.9 \%)$ had more divorced or widowed study subjects as compared other CKD stages. There was also a significant difference in employment status $(p<0.001)$. There were more study subjects who were employed at Stage I ( $n=$ $66.7 \%)$ and at Stage II $(n=59 \%)$. In contrast, Stage VD ( $n=48 \%$ ) had more unemployed study subjects. Duration of illness was significantly different among CKD stages $(p<0.001)$. Post hoc analysis showed that duration of illness at Stage V (mean \pm SD: 17.92 \pm 9.14 ) was significantly longer than Stage I (mean \pm SD: $9.12 \pm 5.83$ ), Stage II (mean \pm SD: $11.10 \pm 6.29$ ), Stage III (mean \pm SD: $13.48 \pm 7.90$ ) and Stage VD (mean \pm SD: $11.48 \pm 7.76$ ). Stage IV (mean \pm SD: $15.75 \pm 7.66)$ had significantly longer duration than Stage I, Stage II and Stage VD. Duration of illness at Stage III was significantly longer than Stage I. There was also a significant difference in number of co-morbidities among CKD stages $(p<0.001)$. Post hoc analysis demonstrated that number of co-morbidities at Stage I (mean \pm SD: $1.53 \pm 0.91$ ) were significantly fewer than Stage III (mean \pm SD: $3.63 \pm 1.39$ ), Stage IV (mean \pm SD: $3.55 \pm 1.14$ ), Stage V (mean \pm SD: $3.62 \pm 1.16)$ and Stage VD (mean \pm SD: $2.54 \pm$ 1.28). Stage II (mean \pm SD: 1.92 \pm 1.18) had significantly fewer than Stage III, Stage IV and Stage V. Number of co-morbidities in Stage VD was significantly less than Stage III, Stage IV and Stage V.

Mean and standard deviation of self-management behaviour score at different stages of CKD were presented in Table 3. One way ANOVA demonstrated that there was a significant difference in mean of self-management behaviour score among CKD stages $(p<0.001)$. Post hoc analysis indicated that mean of self management behaviour score for Stage I (mean \pm SD: $77.81 \pm 9.41)$ was significantly higher than Stage IV (mean \pm SD: $70.53 \pm 13.91$ ) and Stage V (mean \pm SD: $69.54 \pm 12.31)$. Mean of self management behaviour score for Stage II (mean \pm SD: $78.46 \pm$ 10.01) was significantly higher than Stage IV and Stage V.

Predictors of self-management behaviour were shown in Table 4. Simple linear regression identified five significant predictors: age $(p<0.001)$, marital status ( $p=0.013)$, education level $(p<0.001)$, number of co-morbidities $(p<0.001)$ and staging of CKD $(p<$ 0.001). A final model was developed with multiple linear regression using forward method and two significant predictors were identified: education level $(p<0.001)$ and number of co-morbidities $(p=0.01)$.

Table 3 Self-management behaviour score at different stages of chronic kidney disease $(n=300)$.

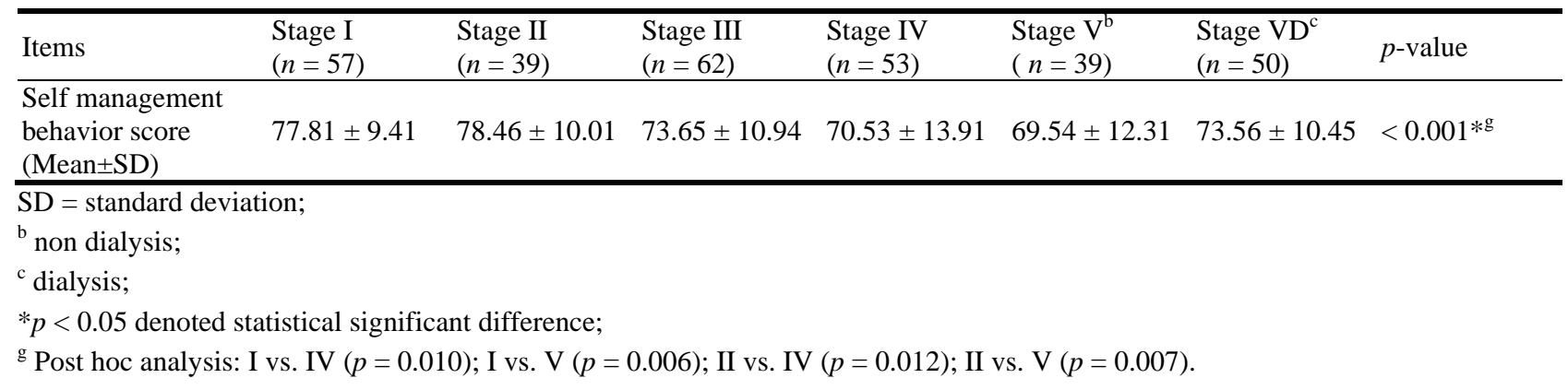


Table 4 Predictors of self-management behaviour $(n=300)$.

\begin{tabular}{lllll}
\hline \multirow{2}{*}{ Variables } & \multicolumn{2}{c}{ Simple linear regression } & \multicolumn{2}{c}{ Multiple linear regression } \\
\cline { 2 - 5 } & $\mathrm{b}^{\infty}(95 \% \mathrm{CI})$ & $p$-value & $\mathrm{b}^{\infty}(95 \% \mathrm{CI})$ & $p$-value \\
\hline Age & $-0.197(-0.270 \sim 0.123)$ & $<0.001^{*}$ & - & \\
Marital status & $-3.016(-5.385 \sim 0.647)$ & $0.013^{*}$ & - & $<.592(5.003 \sim 8.182)$ \\
Education level & $7.220(5.689-8.751)$ & $<0.001^{*}$ & $-1.089(-1.916 \sim 0.262)$ & $0.01^{*}$ \\
No. of co-morbidities & $-2.117(-2.988 \sim 1.245)$ & $<0.001^{*}$ & - & \\
Staging of CKD & $-1.379(-2.138 \sim 0.620)$ & $<0.001^{*}$ & & \\
\hline CI = confidence interval; & & & \\
${ }^{\infty}$ Unstandardised coefficient; & &
\end{tabular}

$24 \%$ of variance in self management score was explained by education level and number of co-morbidities. $\left(R^{2}=0.241, F(2,297)=47.238\right.$, $p<0.001)$ Education level showed positive unstandardised coefficient $(b)$ indicating positive association with self-management behaviour whilst number of co-morbidities showed negative unstandardised coefficient $(b)$ indicating negative association with self-management behaviour.

\section{Discussion}

In this study, a significant difference was found in demographic characteristics (i.e., age, gender, education level, marital status and employment status) and clinical characteristics (i.e., duration of illness and number of co-morbidities) among CKD stages. This was probably because of different primary cause of CKD at early stage and late stage of CKD in which glomerulonephritis with particularly SLE (systemic lupus erythematosus) predominated at early stage of CKD whilst most of the patients at late stage of CKD had primary cause of diabetic nephropathy.

More female at early stage of CKD as noticed in this study might be due to higher frequency of SLE in female gender. The increased prevalence of SLE among female population has been thought to be partly attributed to a complex oestrogen hormonal effect on the immune system [13]. Younger age at early stage of CKD was also observed in this study as SLE patients are generally younger with $65 \%$ of SLE patients have disease onset ranging from 16 to 55 years old [14]. Because of younger age of SLE patients, this had probably explained higher percentage of employed status, higher education level, shorter duration of illness and less co-morbidities as observed at early stage of CKD in this study.

In contrast, patients with diabetic nephropathy who are seen at nephrology outpatient clinic are usually older. This can be probably explained by the increased diabetes prevalence in older population $[15,16]$ and also long standing uncontrolled hyperglycaemia that has been known to be responsible for development of diabetic nephropathy $[17,18]$. In addition to older age, it is not uncommon for patients with diabetes to have multiple co-morbidities. Thus, this probably accounted for the increased number of co-morbidities at late stage of CKD. Because of higher proportion of older patients at late stage of CKD, this has led to increased percentage of widowed status, higher percentage of retired status, lower education level, longer duration of illness and increased number of co-morbidities at late stage of CKD as found in this study.

However, patients at Stage VD (dialysis) were found to be younger than those at Stage IV and Stage $\mathrm{V}$ (non dialysis). This was likely due to selection bias as according to 22nd Report of the Malaysian Dialysis and Transplant Registry 2014, the dialysis treatment rate, per million age group population, is increased by age group with the highest rate for age group of $\geq 65$ years, hence higher mean age for dialysis group is to be expected [19]. Because of the potential selection bias where younger patients were recruited in dialysis group, this probably explained higher percentage of 
patients had higher education, shorter duration of illness, fewer co-morbidities and were single as compared to those at Stage IV and Stage V. However, there were more unemployed patients in dialysis group. This can be owing to more dialysis patients who were student recruited in this study. Besides, since patients who are on dialysis need to spend considerable time and commitment in managing their disease due to complexity of treatment regimen including compliance with medications, dietary restrictions, fluid limitations, catheter exit site care and vascular access care, this reason could render them to choose to be unemployed.

From the results obtained, it can be seen that patients at early stage of CKD are better self managers as compared to those at late stage of CKD but no better or poorer than those at dialysis group. This might be probably due to the different primary cause of CKD at early stage and late stage of CKD which might have different needs and burden of self-management. There were predominantly patients with glomerulonephritis at early stage of CKD whilst most patients were with diabetic nephropathy as primary cause at late stage of CKD at the nephrology clinic. Unlike those with glomerulonephritis, patients with diabetic nephropathy are usually presented with multiple diabetic complications and co-morbidities such as hypertension, dyslipidemia, cardiovascular disease, arthritis, intermittent claudification, visual impairment and depression [20, 21]. As a result, it makes the treatment regimen much more complicated and causes difficulty for the patients to self manage their disease including taking multiple medications, attending multiple medical reviews, monitoring disease symptoms and action to be taken for worsening of symptoms. Besides, complications of diabetes, such as retinopathy, neuropathy, foot ulcers; and co-morbidities can diminish functional ability of the patients which may subsequently contribute to poor self-management behaviour.

Current study revealed that dialysis patients had no better or poorer self-management behaviour than those who were not on dialysis and had better renal function. The dialysis group in this study involved patients on haemodialysis and peritoneal dialysis. Both haemodialysis and peritoneal dialysis patients are expected to follow a complex, prescribed treatment regimen and be compliance with medications, dietary restrictions, fluid limitations, catheter exit site care and vascular access care [22, 23]. Although there was no studies available comparing status of self-management behaviour among CKD stages, haemodialysis had been shown to be low self managers in a cross sectional study [24] and there were very limited studies on evaluation of patients on peritoneal dialysis. In this study, no poorer self-management behaviour was observed in dialysis patients and this might be due to education and counselling services that been given by nurses and dieticians with the purpose to enable them to be better self managers. Besides, peritoneal dialysis patients are usually the selected group of patients, thus they are highly motivated and take greater responsibility for their care [25]. Extensive trainings are also given to these patients before they start home based peritoneal dialysis.

Among the demographic and clinical variables, results showed that education level and number of co-morbidities are the important predictors of self-management behaviour with higher education level exhibiting better self-management behaviour and increased number of co-morbidities showing poorer self-management behaviour. The findings of positive association between education level and self-management behaviour were consistent with those of a study that evaluating self-management behaviour in patients with type II diabetes mellitus [26]. Patients with higher educational background usually have a more positive attitude toward their disease and are more likely to attain better control of disease [27]. Patients with lower education level might tend to have misunderstanding that 
asymptomatic CKD to be not a concern for them which impedes the adoption and implementation of preventing and managing behaviour. Besides, those with low education level are more likely to have low literacy level [28]. Health literacy is the extent to which individuals have the capacity to obtain, process and understand basic health information and services needed to make informed health decisions and limited health literacy prevents patients from engaging in effective self-management [29].

The association of poorer self-management behaviour with increased number of co-morbidities as found in this study may not only be due to complexity of regimens but it may also be due to the possible association of deficits in cognitive function and physical limitation with many chronic diseases which in turn hinder the patients' ability to effectively manage their chronic diseases [30]. Additionally, those patients with repeated hospitalization due to multiple co-morbidities may feel more obstacles for self-management because of their poor health [26].

\section{Conclusions}

This study had highlighted several important findings that can be useful as background information for development of targeted self-management interventions in future to maximize positive outcomes. Nonetheless, there were a few limitations to this study that should be noted. Firstly, it was a cross sectional study, thus it precludes the determination of causal relationships among the factors. Secondly, since convenience sampling was used in this study, it was highly vulnerable to selection bias and the samples collected were unlikely to be representative of the population being studied. Besides, the study subjects who volunteered to participate were likely to be more motivated. Hence, the results obtained cannot be generalized to the population. Nevertheless, convenience sampling method was used due to large sample size required in short duration of period. Last but not least, the instrument used depended on self report, thus it might have bias and it cannot be presumed that the relationships observed reflect self-management assessed by other methods. Future study with stronger research design is warranted to determine the causality between the influencing factors and self-management behaviour. Qualitative research is needed to explore the theories related to behaviour change and to gain a better understanding of the experience of self-management of patients with chronic kidney disease, perhaps focusing on different primary cause of CKD owing to the possible different unique needs, with the purpose of developing self-management support program.

In conclusion, this study demonstrated that patients at late stage of CKD had poorer self-management behaviour as compared to those at early stage of CKD but dialysis patients had no better or poorer self-management behaviour than those who were not on dialysis and had better renal function. Patients at late stage of $\mathrm{CKD}$, especially those with diabetic nephropathy as primary cause of CKD; those with low education level and those with multiple co-morbidities deserve special attention.

\section{Acknowledgments}

We are grateful to the staffs from nephrology outpatient clinic for their assistance during data collection; Dr. Risna Abdul Cader and Miss Shim Yee Wei for their help in statistical analysis.

\section{References}

[1] Hill, N. R., Fatoba, S. T., Oke, J. L., Hirst, J. A., O'Callaghan, C. A., Lasserson, D. S., et al. 2016. "Global Prevalence of Chronic Kidney Disease-A Systematic Review and Meta-Analysis." PLoS One 11 (7): $\mathrm{e} 0158765$.

[2] Fresenius Medical Care. 2014. "ESRD Patients in 2013: A Global Perspective." Fresenius Medical Care. Accessed November 29, 2014. http://www.vision-fmc. com/files/ESRD_Patients_in_2013.pdf.

[3] USRDS (United States Renal Data System). 2012. “2012 Annual Data Report: Atlas of Chronic Kidney Disease and End-Stage Renal Disease in the United States." Bethesda, MD: National Institutes of Health, National 
Institute of Diabetes and Digestive and Kidney Diseases. Accessed November 29, 2014. http://www.usrds.org.

[4] Jha, V., Wang, Y. M., and Wang, H. Y. 2012. "The Impact of Ckd Identification in Large Countries: The Burden of Illness.” Nephrol Dial Transplant 27 (3): iii32-8.

[5] Atkins, R. C. 2005. “The Changing Patterns of Chronic Kidney Disease: The Need to Develop Strategies for Prevention Relevant to Different Regions and Countries.” Kidney International 68 (98): S83-5.

[6] Curtin, R. B., Walters, B.A., Schatell, D., Pennell, P., Wise, M., and Klicko, K. 2008. "Self-Efficacy and Self-Management Behaviors in Patients with Chronic Kidney Disease.” Adv Chronic Kidney Dis. 15 (2): 191-205.

[7] Wu, I. W., Wang, S. Y., Hsu, K. H., Lee, C. C., Sun, C. Y., and Tsai, C. J. 2009. "Multidisciplinary Predialysis Education Decreases the Incidence of Dialysis and Reduces Mortality—A Controlled Cohort Study Based on the Nkf/Doqi Guidelines.” Nephrology Dialysis Transplantation 24 (11): 3426-33.

[8] Battersby, M. W., Ask, A., Reece, M. M., Markwick, M. J., and Collins, J. P. 2003. "The Partners in Health Scale: The Development and Psychometric Properties of a Generic Assessment Scale for Chronic Condition Self-Management.” Australian Journal of Primary Health 9 (3): 41-52.

[9] Lorig, K. 1993 "Self-Management of Chronic Illness: A Model for the Future (Self Care and Older Adults)." Generations 17 (3): 11-4.

[10] Li Wan Po, A. 1998. Statistics for Pharmacists. 1st ed. United Kingdom: Wiley-Blackwell.

[11] National Kidney Foundation/Kidney Disease Outcomes Quality Initiative. 2002. "Kdoqi Clinical Practice Guidelines for Chronic Kidney Disease: Evaluation, Classification and Stratification.” Am J Kidney Dis. 39 (2): S1-266.

[12] Kidney Disease Improving Global Outcomes. 2013. "Kdigo 2012 Clinical Practice Guideline for the Evaluation and Management of Chronic Kidney Disease.” Kidney International Supplements 3 (1): 19-62.

[13] Lahita, R. G. 1999. "The Role of Sex Hormones in Systemic Lupus Erythematosus." Current opinion in rheumatology 11 (5): 352-6.

[14] Rothfield, N. 1981 "Clinical Features of Systemic Lupus Erythematosus.” In Textbook of Rheumatology. Philadelphia: W.B. Saunders.

[15] Shaw, J. E., Sicree, R. A., and Zimmet, P. Z. 2010. "Global Estimates of the Prevalence of Diabetes for 2010 and 2030.” Diabetes Research and Clinical Practice 87 (1): 4-14.

[16] Wu, A. Y. T., Kong, N. C. T., De Leon, F. A., Pan, C. Y.,
Tai, T. Y., Yeung, V. T. F., et al. 2005. “An Alarmingly High Prevalence of Diabetic Nephropathy in Asian Type 2 Diabetic Patients:" The Microalbuminuria Prevalence (Map) Study. Diabetologia 48 (1): 17-26.

[17] Deferrari, G., Repetto, M., Calvi, C., Ciabattoni, M., Rossi, C., and Robaudo, C. 1998. "Diabetic Nephropathy: From Micro-to Macroalbuminuria.” Nephrology Dialysis Transplantatio. 13 (8): 11-5.

[18] Di Landro, D., Catalano, C., Lambertini, D., Bordin, V., Fabbian, F., Naso, A., et al. 1998. "The Effect of Metabolic Control on Development and Progression of Diabetic Nephropathy.” Nephrology Dialysis Transplantation 13 (8): 35-43.

[19] Goh, B. L., Ong, L. M., and Lim, Y. N. 2015. 22nd Report of the Malaysian Dialysis and Transplant Registry 2014. Kuala Lumpur (MY): National Renal Registry.

[20] Assmann, G., and Schulte, H. 1998 "The Prospective Cardiovascular Münster (Procam) Study: Prevalence of Hyperlipidemia in Persons with Hypertension and/or Diabetes Mellitus and the Relationship to Coronary Heart Disease.” American heart journal 116 (6): 1713-24.

[21] Gregg, E. W., Beckles, G. L., Williamson, D. F., Leveille, S. G., Langlois, J. A., Engelgau, M. M., et al. 2000. "Diabetes and Physical Disability among Older Us Adults.” Diabetes Care 23 (9): 1272-7.

[22] Curtin, R. B., Johnson, H. K., and Schatell, D. 2004 “The Peritoneal Dialysis Experience: Insights from Long-Term Patients.” Nephrology Nursing Journal 31 (6): 615-24.

[23] Richard, C. J. 2006. "Self-Care Management in Adults Undergoing Hemodialysis.” Nephrology Nursing Journal 33 (4): 387-94.

[24] Curtin, R. B., Bultman Sitter, D. C., Schatell, D., and Chewning, B. A. 2004. "Self-Management, Knowledge, and Functioning and Well-Being of Patients on Hemodialysis." Nephrology Nursing Journal 31 (4): 378-96.

[25] Hutchison, A. J., and Courthold, J. J. 2011. "Enabling Self-Management: Selecting Patients for Home Dialysis?.” NDT Plus 4 (Suppl 3): iii7-10.

[26] Huang, M. J., Zhao, R., Li, S. Y., and Jiang, X. L. 2014. "Self-Management Behavior in Patients with Type 2 Diabetes: A Cross-Sectional Survey in Western urban China.” PLoS One. 9 (4): e95138.

[27] WHO (World Health Organization). 1999. Definition, Diagnosis and Classification of Diabetes Mellitus and Its Complications. Report of a WHO Consultation, Part 1: Diagnosis and Classification of Diabetes Mellitus. Geneva: World Health Organization.

[28] Kindig, D. A., and Panzer, A. M., 2004. Nielsen-Bohlman L. Health Literacy: A Prescription to End Confusion. Washington: National Academies Press.

[29] Lloyd, L. L. J., Ammary, N. J., Epstein, L. G., Johnson, 
R., and Rhee, K. A. 2006. "Transdisciplinary Approach to Improve Health Literacy and Reduce Disparities." Health Promotion Practic 7 (3): 331-5.

[30] Blaum, C. S., Ofstedal, M. B., and Liang, J. 2002. "Low
Cognitive Performance, Comorbid Disease, and Task-Specific Disability Findings from a Nationally Representative Survey." J Gerontol A Biol Sci Med Sci 57 (8): M523-31. 